\title{
A estrutura molecular e o empacotamento cristalino de uma nova chalcona metoxilada
}

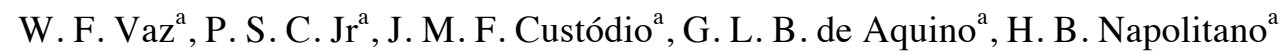 \\ ${ }^{a}$ Ciências Exatas e Tecnológicas, Universidade Estadual de Goiás, Anápolis, GO, Brazil.
}

As chalconas metoxiladas, ou metóxi-chalconas, são conhecidas como compostos promissores por apresentarem várias propriedades biológicas ${ }^{[1]}$. Quimicamente, uma chalcona consiste de dois anéis aromáticos unidos por um sistema $\alpha, \beta$ insaturado altamente eletrofílico ($\mathrm{CO}-\mathrm{CH}=\mathrm{CH}-$ ). Normalmente, esse esqueleto assume uma conformação linear ou quase planar. No entanto, a presença de grupos substituintes apropriados nos anéis aromáticos pode modificar a distribuição eletrônica na molécula, o que leva a propriedades diversas ${ }^{[2]}$.

Uma ampla análise da nova metóxi-chalcona (E)-3-(4-etilfenil)-1-(4-metóxifenil)prop2-an-1-ona, $\mathrm{C}_{18} \mathrm{H}_{18} \mathrm{O}_{2}$, é apresentada via difração de raios-X. Esse composto centrossimétrico cristaliza no grupo espacial $\mathrm{P} 2 / 1 / \mathrm{c}$, com quarto moléculas por cela unitária, apresentando a seguinte métrica: $a=19.5245(6) \AA, b=5.8442(10) \AA, c=13.0903(4) \AA$ and $\alpha=\beta=90^{\circ}$ e $\gamma=$ $92.2050^{\circ}(10)$. Sua estrutura molecular apresenta três partes consideradas planares, os dois anéis aromáticos e a porção enona, mas a análise conformacional mostra que o anel A apresenta uma torção de $15.14^{\circ} \mathrm{em}$ relação ao anel $\mathrm{B}$, resultando em uma molécula não planar. Além disso, o grupo metóxi é coplanar ao anel A [179.47(2) ${ }^{\circ}$, na Figura 1 tem-se a representação Ortep, com probabilidade de $50 \%$, para a $\mathrm{C}_{18} \mathrm{H}_{18} \mathrm{O}_{2}$. Os grupos insaturados e o grupo cetona apresentam uma orientação sinperiplanar com um ângulo de torção de 15.14(8) ${ }^{\circ}$ para os átomos O1-C9-C8-C7. O ângulo diedro entre os anéis benzênicos é $12.18(7)^{\circ} \AA$, correspondendo a uma conformação cisóide.

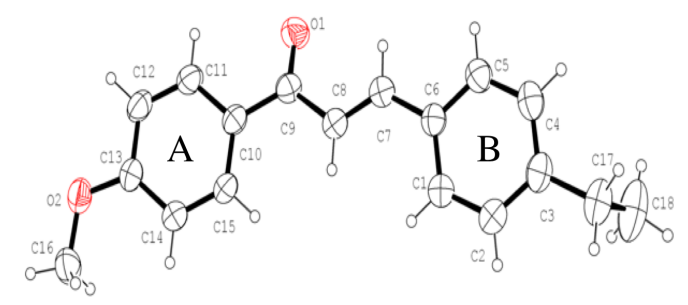

Figura 1: Representação Ortep, com 50\% de probabilidade, mostrando a numeração para a

$$
\mathrm{C}_{18} \mathrm{H}_{18} \mathrm{O}_{2} \text {. }
$$

O grau de planaridade dessa metóxi-chalcona pode ser entendido pelo equilíbrio entre a estabilização das forças intermoleculares - conjugação em toda a molécula e a repulsão estérica entre os substituintes ligados aos anéis aromáticos. As moléculas de $\mathrm{C}_{18} \mathrm{H}_{18} \mathrm{O}_{2}$ se empacotam devido aos fracos contatos intermoleculares $\mathrm{CH} \cdots \pi$ e $\mathrm{CH} \cdots \mathrm{O}$, orientados principalmente pelo grupo metóxi, ver Figura 2.

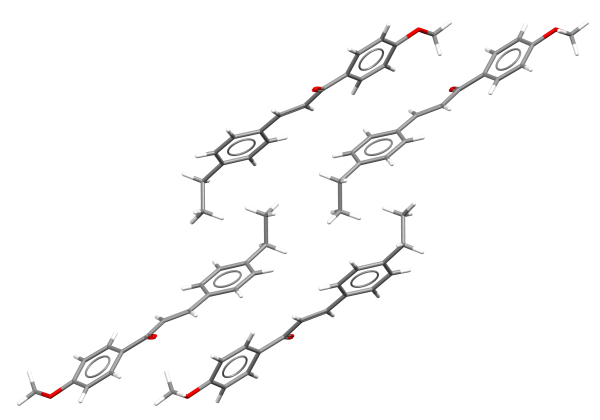

Figura 2: Representação do empacotamento cristalino, ao longo do eixo [010], da $\mathrm{C}_{18} \mathrm{H}_{18} \mathrm{O}_{2}$. 
A interação C16-H16C ‥ O2 forma uma associação dimérica entre moléculas adjacentes em - $\mathrm{x},-\mathrm{y},-\mathrm{z}+2$ enquanto que C18-H16B $\cdots \mathrm{O} 1[\mathrm{x},-\mathrm{y}-1 / 2,+\mathrm{z}+1 / 2], \mathrm{C} 8-\mathrm{H} 8 \cdots \mathrm{O} 1[\mathrm{x},+\mathrm{y}+1,+\mathrm{z}]$ e $\mathrm{C} 15-$ H15 ‥ Cg (Tabela 1) são responsáveis por criar uma rede tridimensional de empacotamento desses dímeros.

Tabela 1: Ligações de Hidrogênio e "short contacts" para $\mathrm{C}_{18} \mathrm{H}_{18} \mathrm{O}_{2}$.

\begin{tabular}{lllc}
\multicolumn{1}{c}{$\mathrm{D}-\mathrm{H} \cdots \mathrm{O}$} & $\mathrm{D} \cdots \mathrm{A}$ & $\mathrm{H} \cdots \mathrm{A}$ & $\mathrm{D}-\mathrm{H} \cdots \mathrm{A}$ \\
\hline $\mathrm{C} 8-\mathrm{H} 8 \cdots \mathrm{O} 1^{(\mathrm{i})}$ & 3.797 & 2.994 & 145.56 \\
$\mathrm{C} 18-\mathrm{H} 16 \mathrm{~B} \cdots \mathrm{O} 1^{(\text {ii) }}$ & 3.314 & 2.589 & 132.35 \\
$\mathrm{C} 18-\mathrm{H} 16 \mathrm{C} \cdots \mathrm{O} 2^{\text {(iii) }}$ & 3.429 & 2.646 & 139.02 \\
$\mathrm{C} 15-\mathrm{H} 15 \cdots \mathrm{Cg}$ & 3.663 & 3.001 & 129.47 \\
\hline Códigos de Simetria: (i) & $\mathrm{x},+\mathrm{y}+1,+\mathrm{z}$ (ii) $\mathrm{x},-\mathrm{y}-1 / 2,+\mathrm{z}+1 / 2$ (iii) & $-\mathrm{x},-\mathrm{y},-\mathrm{z}+2$ &
\end{tabular}

$\mathrm{Na}$ estrutura molecular dessa metóxi-chalcona, o contato entre os grupos metóxi e carbonil é fundamental para a orientação do ângulo C7-C8-C9-C10. Além disso, a adição de grupos como substituinte implica em interações mais fracas, como contato $\pi-\pi$.

[1] Bandgar, B.P. et al., Bioorganic \& Medicinal Chemistry, 18(3), p. 1364-1370 (2010).

[2] Prasad, Y.R., Rao, A.L., Rambabu, R., E-Journal of Chemistry, 5(3) p. 461-466. (2008).

Acknowlegments: FAPEG; UEG. 